\title{
Postnatal Care Service Utilization and Associated Factors Among Mothers Who Gave Birth in Last Year: Community Based Cross Sectional Study in Adama, Ethiopia
}

\author{
Senait Ayalew G/Silasie ${ }^{1, *}$, Sileshi Garoma Abeya ${ }^{2}$, Ebrhaim Mohammed Gebaba ${ }^{2}$ \\ ${ }^{1}$ East Shaw Zonal Health Department, Adama, Ethiopia \\ ${ }^{2}$ Public Health Department, Adama Hospital Medical College, Adama, Ethiopia \\ Email address: \\ ayalewsenait@gmail.com (S. A. G/Silasie), garomaabe@gmail.com (S. G. Abeya), ebrahim.m805@gmail.com (E. M. Gebaba) \\ ${ }^{*}$ Corresponding author
}

To cite this article:

Senait Ayalew G/Silasie, Sileshi Garoma Abeya, Ebrhaim Mohammed Gebaba. Postnatal Care Service Utilization and Associated Factors Among Mothers Who Gave Birth in Last Year: Community Based Cross Sectional Study in Adama, Ethiopia. American Journal of Nursing Science. Vol. 10, No. 5, 2021, pp. 227-236. doi: 10.11648/j.ajns.20211005.13

Received: August 21, 2021; Accepted: September 24, 2021; Published: September 29, 2021

\begin{abstract}
Background: Postnatal period is generally the most neglected period, especially in developing countries. This study assessed postnatal care service utilization and associated factors among mothers who gave birth in the last one year in Adama Town, Oromia, Ethiopia. Methods: Community based Cross sectional study was employed in seven randomly selected kebeles ' in Adama town. A total of 563 mothers was included. Data was collected by face to face interview. Data were entered into Epi Info version 7 and imported to SPSS version 20. Descriptive statistics were carried out to characterize the study population. Bivariate and Multivariable Logistic regression were used to identify the associated factors. Result: The mean age of respondents was 28 ( $\mathrm{SD} \pm 5.01)$ Years. The prevalence of PNC utilization was 269 (47.7\%) with (95\% CI: 44.0, 51.8). Educational status (AOR, 2.27; 95\% CI: 1.13, 4.57), mode of delivery (AOR, 5.08; 95\% CI: 2.55, 10.10), Provision of PNC appointment (AOR, 2.09; 95\% CI: 1.36, 3.25), and Mothers Knowledge (AOR, 5.68; 95\%CI: 2.97, 10.87) showed statistically significant association with PNC service utilization. Conclusion: Postnatal care service utilization in this study is much lower than Health service transformation plan of the country. Factors like Educational status, Mode of Delivery, Appointment date, mother's knowledge of PNC utilization were found to be significantly associated with PNC utilization.
\end{abstract}

Keywords: PNC Services, Utilization, Adama Town

\section{Introduction}

Postnatal care (PNC) is defined as a care given to the mother and her newborn baby immediately after the birth of the placenta to the first six weeks of life. PNC interventions are used for prevention of impairments and reduction of maternal and newborn mortality. [1, 2] World Health Organization (WHO) recommends a total of four visits: on the first day (24 hours), $3^{\text {rd }}$ day (48-72 hours), between 6-7 days and $6^{\text {th }}$ weeks. Indeed, these contacts can be exercised in a health facility after discharge by Health care practitioners [3].

According to the $\mathrm{WHO}$, only a small proportion of women in developing countries, less than $30 \%$, receive postnatal care and in very poor countries and regions, as few as 5\% of women receive such care [4]. Maternal mortality ratio (MMR) is 15 times higher in developing than in developed regions (16/100,000 live births) [5]. Sub-Saharan African countries (SSA) had the highest MMR 500 maternal deaths per 100,000 live births and current studies in Ethiopia showed that 46,000 mothers and 48 per 1,000 live births are died $[6,7]$.

Study conducted in Brazil shows higher percent of women utilize postnatal care service more than many other developing counties, which is $77 \%$. Study done in Shinyanga, India, rural district only $35 \%$ of women in the area visits health facilities for PNC services for at least once within 42 days [8]. In another study conducted in Tertiary Care Center of Delhi, Only 9.3\% of women received postnatal care service after discharge from health institution [2]. In Kiambaa Sub County (75\%), Bangladesh (73\%), Nepal (72\%) and Rwanda (71\%) of women did not 
receive any PNC service. another Study from Tanzania indicated low utilization of maternal PNC services among women [9].

Studies from developing countries shows that low level of PNC utilization; Uganda (57\%), Haiti (55\%), Mali (49\%), Nigeria (46.5\%), Cambodia (46\%), Kenya (46\%), Burkina Faso (44\%), Malawi (41\%) and Zambia (41\%) didn't utilize PNC [9]. Ethiopian Demographic Health Survey (EDHS) shows that, the level of PNC service utilization coverage is extremely low, only $18 \%$ of women received PNC service within forty two days in a recommended timings. Among $18 \%$, only $8 \%$ followed care within four hours of delivery, $3 \%$ within 4 to- 23 hours, $2 \%$ within $1-2$ days, and 5\% within 3-42 days of delivery, In Oromia region, Ethiopia, only 9\% of women utilized PNC service within 42 days of delivery, this is below the national level [10]. Studies conducted in different parts of Ethiopia showed low level (Somali region 8.4\%, Denbecha 9.3\%, Abi Adi 11.9\%, Jabitena district 20.2\%, Debre Markos Town 33.5\%, Wolaita Zone,34.9\%, Lemo woreda $51.4 \%$ ), but high level of PNC utilization have been shown in Gondar Zuria district (66.8\%) and in Adwa town $(78.3 \%)$ [4, 5, 7, 11-14].

Study conducted in different area show that, factors like: Socio-demographic factors, (age, religion, occupation, education, Marital status, Family Income), Reproductive and Obstetric factors, like ANC follow up, Parity and gravidity, Prenatal follow up, delivery and post delivery related complications, mode of delivery, Advice and appointment on discharge significant association with PNC utilization $[4,7$, $13,15,16]$.

Study done in Ruwanda show that older age of women was associated with low PNC utilization [17]. But in study conducted Bahi District (Tanzania), and Ethiopia (Lemo wereda, Dembecha, AbiAdi, Tigray and Holeta Town) maternal Age was not associated with PNC service utilization [5, 8, 11, 18] Whereas studies conducted in Jijiga Town, Somali Regional State, Eastern Ethiopia, in Wolaita Zone, Southern Ethiopia, showed that young mothers were 3.5 times more likely to use antenatal and postnatal care service, Study done in Kenya show that marital status has no association with PNC service utilization [19]. But study in Ruwanda shows that, being married were associated with PNC utilization, that is similar with the result of study conducted in selected health centers, Addis Ababa, Ethiopia at (Entoto Fna Health Center, Gulele district) [4].

Whereas study in Tigray region, and in Jigjiga Town, Somali Regional State, Ethiopia, showed that marital status was highly significant association with utilization of maternity health service. This finding is similar with study conducted in Jabitena district, Amhara region [5, 13].

In study conducted in India, maternal occupation has significant association with utilization of postnatal services [20]. Study conducted in Jabitena district and Assosa district showed that maternal occupation was not associated with PNC service [21].

Study from Ruwanda, Tanzania showed that economic status of women had statistically significant association with PNC utilization and Women from high income households were nearly 2 times more likely to use PNC services [22, 23]. Study conducted in Gulele district, Addis Ababa and AbiAdi Tigray Region, showed that good income level of women were significantly associated with PNC utilization [4, 18].

Study conducted in Delhi, Tanzania, Kenya, Uganda, and Indonesia and in Ethiopia (Gulele, in selected health center of Adiss Abeba, jabitna, Amhara rigion) shows that educational status of women was significantly association with PNC utilization [8, 12, 19, 21, 23].

A Community Based Mixed Study show that mothers who have good knowledge of postnatal care service utilization were more than 7 times more likely to utilize PNC service than those who have poor knowledge. Study conducted in Lemo distric of Hadiya zone, Debre Markos town, Jabitena District, Amhara Region showed that Knowledge on maternal complications during postnatal period were significantly associated with postnatal care service utilization [5]. In Gulele, Adiss Ababa, study showed that good Knowledge about postnatal care during antenatal care had significant effect on postnatal health care utilization, and knowing at least one danger sign of post-partum showed statistically significant association with postnatal health care service utilization [4, 24]. Study in Tanzania and Kenya shows that Mothers who attended four or more ANC visits were more likely to use PNC services compared with mothers who did not attend ANC at all [14, 23] And in Ethiopia, study conducted in Wolaita Zone, Southern Region, showed that, ANC service utilization at last pregnancy has shown statistically significant association [11]. In Gulele, Addis Ababa study shows, attending ANC had significant association on postnatal health care utilization [4]. Women who were getting antenatal and delivery care might have a positive association on the uptake of postnatal care which is similar with the studies conducted in Gondar Zuria district, Amhara region [7, 14].

Study done in Lemo woreda shows, mothers who delivered by cesarean section were more likely to utilize PNC than mothers who delivered by spontaneous vaginal delivery (SVD) [5]. Similarly study in Debremarkos Town shows, mothers who delivered by cesarean section were 4.8 times more likely to get postnatal care services than mothers who delivered by SVD [24]. Study in selected Health center in Adiss Ababa, women who utilized PNC service in their previous delivery was more likely to utilized current PNC service [9]. The probability of utilizing postnatal care among women multigravida was decreased compared to Primegravid women [21].

In Lemo werda past history of maternal complication and PNC service utilization is significant, that is mothers who experienced obstetric problems during their last birth appear strongly motivated to seek postnatal care service [5]. Similarly in Debremarkos study conducted indicate that having delivery complication during child birth were 2.58 times more likely to utilize postnatal care services [24]. Study conducted In Abi Adi Town Tigry show that 
mothers who know maternal postpartum period complications are more likely to have used postnatal care services [18]. Whereas in Jabitena district, mothers who had knowledge of at least one postpartum obstetric danger sign were 4 times more likely to utilize postnatal care service [21].

Place of delivery has also been an important role of postnatal care service utilization. Mothers who gave their last child birth in health institutions were about 4 times more likely to utilize postnatal care service [20]. Study conducted in Addis Ababa shows place of delivery of their last baby have significant association with utilization of PNC services [9, 11]. Another studies, in Jibatena and Debre Markos, Amhara Region, shows that Mothers who gave birth their last child in health institutions were about 4 times and 1.68 times more likely to utilize postnatal care service respectively $[21,24]$. Study conducted in Debremarkos Town shows, live birth outcome were 2.7 times more likely to get postnatal care services than mothers who gave stillbirth [14].

Ethiopia is the second most populous country with over 100 million people [25]. And one of the poorest in Reproductive Health Service (RHS) levels as indicated by high rates of maternal morbidity and mortality. To address this problem, the country has had a significant expansion of health care facilities with more than 35,000 community health workers called Health Extension Workers (HEW) mainly engaged in maternal and child health activities [14]. Despite the Ethiopian government's effort to improve maternal health by increasing accessibility to health service but health service utilization is "unacceptably low" [26]. PNC coverage was limited to only $5 \%$ of the expected deliveries which was $4 \%$ less than Skilled Birth Attendants (SBA) coverage [13, 27]. In this study, we tried to assess Postnatal Care Service Utilization and Associated Factors among Mothers Who Gave Birth in the Last One Year In Adama Town, Oromia, Ethiopia.

\section{Methods and Materials}

\subsection{Study Area}

The study was conducted in Adama Town, Oromia Region, Ethiopia, which is located $99 \mathrm{~km}$ Southeast of Addis Ababa, Ethiopia. Adama town has 14 urban and 4 rural kebeles. The town has a total population of 341,796 , 170,842 (50\%) males and 170,953 (50\%) females, Adama Town has 1 government hospital, 7 government health centers, 4 private hospitals, 94 private clinics, 2 NonGovernmental RH clinics and 108 drug stores and Pharmacies. PNC service is being delivered in all hospitals, government health centers, and Non-Governmental clinics and $\mathrm{MCH}$ Special Private Clinics.

\subsection{Study Design and Period}

Community based cross-sectional study design was employed to determine the level of postnatal care service utilization and associated factors among mothers in Adama Town, Oromia Region, Ethiopia from October $1 / 2020$ to December 30/2020.

\subsection{Source Population}

All women of reproductive age (15-49 years) who live in Adama town.

\subsection{Study Population}

All women of reproductive age (15 to 49 years), who gave birth in the last one year before the study period.

\subsubsection{Inclusion Criteria}

Mothers who gave birth within one year and who have voluntarily agreed to participate in the study were included.

\subsubsection{Exclusion Criteria}

Mothers who were not mentally capable of being giving information for interviewer and Mothers who gave birth to baby before one year were also excluded.

\subsection{Sample Size Determination and Sampling Procedures}

\subsubsection{Sample Size Determination}

The required sample size of this study was determined using single population proportion formula. Proportion of PNC utilization of 33.5\% [24]. Margin of error, confidence level and non-response rate was assumed to be $4 \%, 95 \%$ and $5 \%$ respectively.

$$
\mathrm{n}=\frac{\mathrm{Z}(\alpha / 2)^{2} \mathrm{p}(1-\mathrm{p})}{\mathrm{d}^{2}}=535
$$

After adding a 5\% non-response rate to determine the final sample size is 563 for the study.

\subsubsection{Sampling Procedure}

Cables were stratified into two (Urban and rural). Then, from all stratums a totals of seven Kebeles were randomly selected. The Sample size was allocated proportionally to each selected kebeles. The initial interviewed household was selected by simple Random Sampling from the kebele. The subsequent households were selected every $10^{\text {th }}$ household. In the case of no eligible woman identified in the selected household, the next household was visited. Whenever, more than one eligible respondent found in the same selected household only one respondent was chosen by lottery method to avoid intra household correlation. Revisits were made in case eligible respondents were not available at the time of the data collection. In the absence of child bearing woman in sampled household, interviewer interviewed a woman who lives in the next household.

Total participants allocated for each selected kebeles were calculated by the formula of

$$
\mathrm{n}_{\mathrm{f}}=\mathrm{n} / \mathrm{N} \times \text { sample size, }
$$

and gave that: 


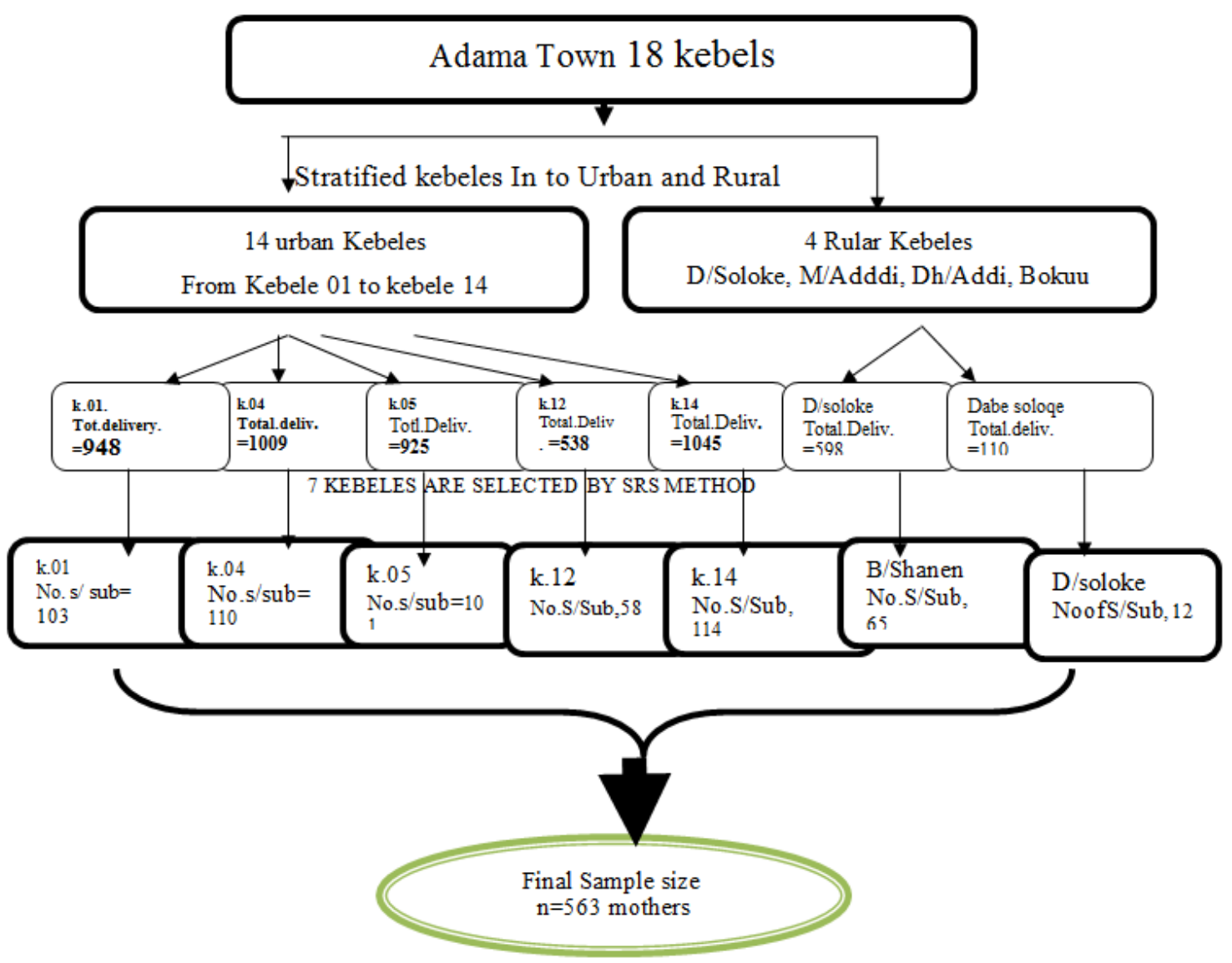

Figure 1. Schematic Presentation of sampling Procedure of the study participant In Adama Town in 2020.

\subsection{Data Collection Procedures (Instruments, Personnel, Measurements)}

Structured and semi structured questionnaire was adapted after reviewing relevant studies. The questionnaire was prepared in English then translated into local languages (Afan Oromo and Amharic), then back to English in order to ensure its consistency. The final version of the questionnaire was used for data collection. Five university students were recruited as interviewers and two BSC Nurses were recruited as supervisors. Data collection was conducted by a face to face interview with women having less than one year's old child at the participant home.

\subsection{Data Quality Assurance}

Two days training was given for both data collectors and supervisors. To check the clarity and validity of the questionnaire and gap in data collection, Pre-test was conducted on $5 \%$ of the study population out of selected kebeles. Discussion was made based on the result of the pretest to make necessary corrections. During data collection the principal investigator \& supervisors checked the data for its completeness, accuracy and clarity on daily bases.

\subsection{Data Processing and Analysis}

The questionnaire was checked for completeness, cleaned, coded and entered into epi-info version 7 and finally exported to SPSS version 20 software for analysis. Frequency table, proportion and numerical summary measures were used to describe the study variables. Bivariate logistic regression was used to see a significant association between the outcome and independent variables. The variables with $\mathrm{p}$ value of $<0.25$ on bivariate analyses were taken to multivariable logistic regression to identify the independent predictors of PNC utilization. Collinearity and Assumption of goodness of fit were checked using Hoshmer and lemshow test.

Finally, the model was built with backward elimination with $95 \%$ confidence level with its corresponding p-value $<0.05$ and was considered statistically significant. To indicate strength of association, the odds ratio was used as a measure of effect and results from the multivariable logistic regression was reported in the form of adjusted odds ratios (AORs).

\section{Results}

\subsection{Socio-Demographic Characteristics of Participants}

A total of 563 mothers of reproductive age who gave birth in the last one year prior to this study were interviewed with a $100 \%$ response rate. $(36.9 \%)$ participants were at the age of 25-29 years with the mean age of the respondents was 28.00 
( $\mathrm{SD} \pm 5.01)$ years. Regarding the religion of study participants, $270(48.0 \%)$ of them were orthodox, Concerning ethnic group $245(43.5 \%)$ were Oromo in the area. Regarding to the marital status of respondents $469(83.3 \%)$ was married. Concerning to educational status $186(33.0 \%)$ was at the level of secondary school and participant husband's educational status, 158 $(33.7 \%)$ were attended secondary school, regarding their Occupational status more than one-third 220 (39.1\%) of respondents were Housewives and 182 (38.\%). The respondent husbands were employed. (For detail description sees Table 1).

\subsection{Reproductive and Obstetric Characteristics}

More than half (68.1\%) of respondents were multigravida and $518(92.0 \%)$ of participants had at least one ANC follow up during their current birth. As to mode of delivery, Three-fourth (79.3\%) of respondents delivered by spontaneous vertex delivery, followed by Cesarean section $104(18.6 \%)$. Of mothers $552(98.0 \%)$ gave birth to their last child in health institution. Regarding obstetric complication, less than one-fourth 116 (20.6\%) of respondents experienced at least one complication after delivery. Regarding to advice and telling appointment date before discharge from health facility, $279(50.3 \%)$ of respondents was advised about PNC service and more than $1 / 3^{\text {rd }}$ of mothers $200(36.3 \%)$ were appointed to return back to PNC service (Table 2).

Table 1. Socio-demographic characteristics of respondents in Adama Town, Oromia Region, Ethiopia, 2020 (N=563).

\begin{tabular}{|c|c|c|}
\hline Variables & Frequency & Percent \\
\hline \multicolumn{3}{|l|}{ Age of respondents (Years) } \\
\hline$<20$ & 62 & 11.0 \\
\hline $20-24$ & 93 & 16.5 \\
\hline $25-29$ & 208 & 36.9 \\
\hline $30-34$ & 130 & 23.2 \\
\hline$>35$ & 70 & 12.4 \\
\hline \multicolumn{3}{|l|}{ Religion } \\
\hline Orthodox & 270 & 48.0 \\
\hline Muslim & 174 & 30.9 \\
\hline Protestant & 114 & 20.2 \\
\hline Other* & 5 & 0.9 \\
\hline \multicolumn{3}{|l|}{ Ethnicity } \\
\hline Oromo & 245 & 43.5 \\
\hline Amhara & 157 & 27.9 \\
\hline Gurage & 105 & 18.7 \\
\hline Other** & 56 & 9.9 \\
\hline \multicolumn{3}{|l|}{ Marital Status } \\
\hline Single & 41 & 7.3 \\
\hline Married & 469 & 83.3 \\
\hline Divorced/Widowed & 53 & 9.4 \\
\hline \multicolumn{3}{|c|}{ Educational Status of Respondents } \\
\hline No formal Education & 74 & 13.3 \\
\hline Primary Education & 157 & 27.8 \\
\hline Secondary School & 186 & 33.0 \\
\hline Above Secondary school & 146 & 25.9 \\
\hline \multicolumn{3}{|l|}{ Occupation of respondent } \\
\hline Employee & 187 & 33.2 \\
\hline Merchant & 121 & 21.5 \\
\hline Daily Laborer & 35 & 6.2 \\
\hline House Wife & 220 & 39.1 \\
\hline \multicolumn{3}{|c|}{ Husband Educational status $(\mathrm{N}=469)$} \\
\hline No formal Education & 15 & 3.2 \\
\hline Primary Education & 126 & 26.9 \\
\hline Secondary Education & 158 & 33.7 \\
\hline Above secondary Education & 170 & 36.2 \\
\hline \multicolumn{3}{|l|}{ Husband Occupational status } \\
\hline Employee & 182 & 38.8 \\
\hline Merchant & 110 & 23.5 \\
\hline Daily Laborer & 148 & 31.5 \\
\hline Work Less & 29 & 6.2 \\
\hline
\end{tabular}

NB-Other *- Jehovah witness, Waqefeta, Other**-Siltii, Tigrai, Welaita, kmbata. 
Table 2. Obstetric and Reproductive characteristics of mothers who give birth in the last one year prior the study in Adama Town, Oromia Region, Ethiopia (2020).

\begin{tabular}{|c|c|c|}
\hline Variables & Frequency & percent \\
\hline \multicolumn{3}{|l|}{ Parity $(\mathrm{N}=563)$} \\
\hline Primi-Para & 180 & 31.9 \\
\hline Multi-Para & 383 & 68.1 \\
\hline \multicolumn{3}{|c|}{ ANC Utilization during current pregnancy } \\
\hline Yes & 518 & 92.0 \\
\hline No & 45 & 8.0 \\
\hline \multicolumn{3}{|l|}{ Mode of Delivery } \\
\hline Instrumental Delivery & 12 & 2.1 \\
\hline Cesarean section & 104 & 18.6 \\
\hline \multicolumn{3}{|l|}{ Place of Delivery } \\
\hline Home Delivery & 11 & 2.0 \\
\hline Institutional Delivery & 552 & 98.0 \\
\hline \multicolumn{3}{|l|}{ Birth Outcome } \\
\hline Still Birth & 9 & 1.5 \\
\hline \multicolumn{3}{|c|}{ Delivery complication during current pregnancy } \\
\hline Yes & 97 & 17.2 \\
\hline No & 466 & 82.8 \\
\hline \multicolumn{3}{|c|}{ Postnatal complication during current pregnancy } \\
\hline Yes & 116 & 20.6 \\
\hline No & 447 & 79.4 \\
\hline \multicolumn{3}{|c|}{ Advised about PNC before discharge $(\mathrm{n}=552)$} \\
\hline Yes & 279 & 50.5 \\
\hline No & 273 & 49.5 \\
\hline \multicolumn{3}{|c|}{ Appointment for Postnatal service Utilization $(n=552)$} \\
\hline Yes & 200 & 36.3 \\
\hline No & 352 & 63.7 \\
\hline
\end{tabular}

\subsection{Utilization of Postnatal Care Service Among Mothers}

Of the total respondents $268(47.6 \%)$ with (95\% CI: 44.0, 51.8) mothers utilized postnatal care service. With regard to attending time of PNC only $12(4.5 \%)$ of mothers use the PNC service within 48 hours and 200 (74.7\%) mothers were visiting one time. Concerning source of information, the majority 177
$(66.0 \%)$ of respondents got information from Mass midia (TV/Radio), followed by during ANC follow up 68 (25.4\%) and others from their friends and rilatives $23(8.6 \%)$. Overall, 295 (52.3\%) of mothers did not use Postnatal care service at their last delivery. The reason explained by participants were, the majority $133(45.1 \%)$ of them had lack of information on the importance of PNC service.

Table 3. Respondents Postnatal care service utilization of mothers in Adama Town, Oromia regional state, Ethiopia, 2020 ( $n=268)$.

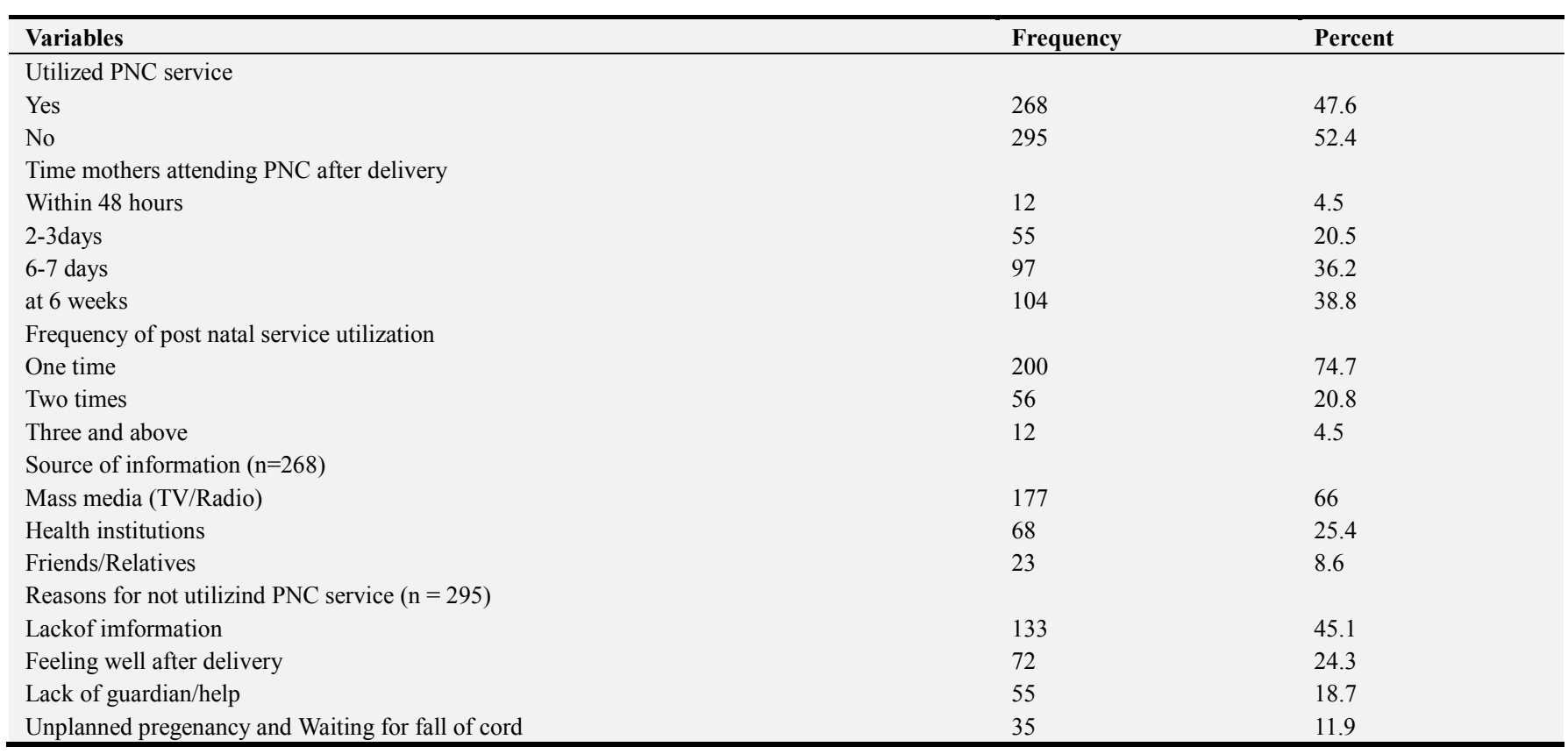




\subsection{Attitude of Respondents About PNC Services Utilization}

To asses mother's attitude, a 5-point Likert scale type questions were prepared. Of the study respondents 347 $(61.7 \%)$ were agreed that advice about PNC service should be provided during ANC follow up. About 288 (51.2\%) of mothers agreed on PNC importance and that it can minimize morbidity and mortality of mothers and newborn. Regarding to the time of PNC service follow up 376 (66.8\%) of mothers agreed to use PNC within 42 days, whereas, 53 (9.4\%) were neutral whether the time is 42 days or not. The majority 411 $(73.0 \%)$ of mothers has a positive attitude toward PNC utilization.

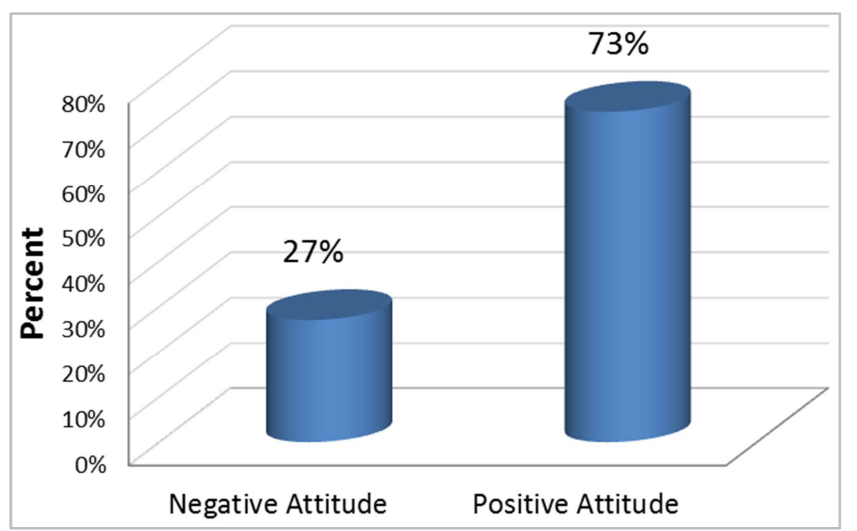

Figure 2. Level of attitude among mothers toward PNC utilization in Adama town.

\subsection{Respondent's Knowledge Level About Postnatal Care Utilization}

More than half 297 (52.8\%) of mothers have not heard information about PNC, and 331 (58.8\%) mothers did know the correct time when to use PNC service. 318 (56.5\%) of mothers know about the recommended number of PNC service follow up. Two third $341(60.6 \%)$ of mothers did know the service provided during their postnatal period. From all PNC users, 198 (35.1\%) had moderate knowledge, $261(46.4 \%)$ low knowledge and the least $104(18.5 \%)$ high knowledge.

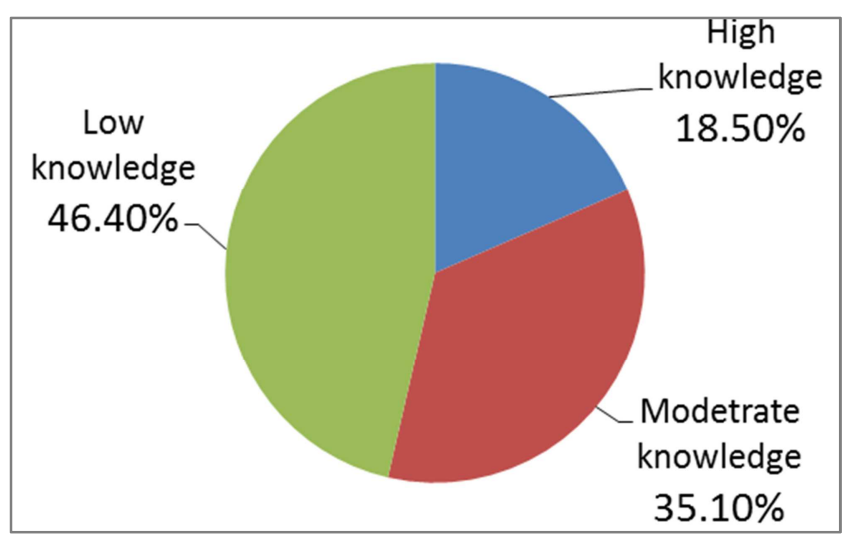

Figure 3. Knowledge level of women toward PNC utilization in Adama town.

\subsection{Factors Associated with PNC Service Utilization}

To identify the association of independent variables with dependent variable both bavariate and multi variable logistic regression analysis was used. The variables that had significant association to the dependent variables at $\mathrm{P}$-values less than 0.25 were entered into multi variable logistic regression. Only four of them (Maternal Education, Mode of delivery, Appointment for PNC service and Respondents Knowledge about PNC service Utilization) has shown a statistically significant association at $\mathrm{P}<0.05$.

Mothers who attend above secondary school were more than 2 times (AOR, 2.09; 95\% CI: 1.09, 3.98) more likely to utilize postnatal care service compared to those having no formal education mothers. The odds of having postnatal care appointment date after delivery were 2.6 times (AOR, 2.55; $95 \%$ CI: $1.71,3.82)$ more likely to use postnatal care service than their counterparts.

Similarly, those mothers who gave birth by cesarean section were 5 times (AOR, 4.87; 95\% CI: 2.77, 8.57) more likely to utilize postnatal care service compared to mothers who gave birth by spontaneous vaginal delivery. Mothers having high Knowledge about PNC importance were 4 times (AOR, 4.07; $95 \%$ CI: $2.30,7.22$ ) more likely to utilize PNC service compared to those mothers who have low Knowledge.

Table 4. Factors associated with PNC utilization among respondents in Adama town, Oromia Region, Ethiopia, 2020.

\begin{tabular}{|c|c|c|c|c|}
\hline \multirow{2}{*}{ Variables } & \multicolumn{2}{|c|}{ PNC service Utilization } & \multirow{2}{*}{ COR $(95 \%$ CI) } & \multirow{2}{*}{$\operatorname{AOR}(95 \% C I)$} \\
\hline & No $(\%)$ & Yes $(\%)$ & & \\
\hline \multicolumn{5}{|c|}{ Marital Status of Respondents } \\
\hline Single & $27(65.9)$ & $14(34.1)$ & $1: 00$ & $1: 00$ \\
\hline Married & $231(49.2)$ & $238(50.8)$ & $1.98(1.06,4.01)^{*}$ & $1.89(0.88,4.08)$ \\
\hline Divorced/Widowed & $36(67.9)$ & $17(32.1)$ & $0.91(0.39,2.24)$ & $0.68(0.25,1.86)$ \\
\hline \multicolumn{5}{|c|}{ Education Status of respondents } \\
\hline No formal Education & $47(63.5)$ & $27(36.5)$ & $1: 00$ & $1: 00$ \\
\hline Primary education & $100(63.7)$ & $57(36.3)$ & $0.99(0.54,1.69)$ & $0.87(0.46,1.64)$ \\
\hline Secondary education & $94(50.5)$ & $92(49.5)$ & $1.70(0.95,2.85)$ & $1.55(0.84,2.84)$ \\
\hline Above secondary school & $54(37.0)$ & $92(63.0)$ & $2.97(1.61,5.09)^{*}$ & $2.09(1.09,3.98) * *$ \\
\hline \multicolumn{5}{|l|}{ No of Deliveries } \\
\hline Primi-Para & $112(62.2)$ & $68(37.8)$ & $1: 00$ & $1: 00$ \\
\hline Multi-Para & $182(47.5)$ & $201(52.5)$ & $2.06(1.09,2.25)^{*}$ & $1.50(0.99,2.29)$ \\
\hline
\end{tabular}




\begin{tabular}{|c|c|c|c|c|}
\hline \multirow{2}{*}{ Variables } & \multicolumn{2}{|c|}{ PNC service Utilization } & \multirow{2}{*}{$\operatorname{COR}(95 \% \mathrm{CI})$} & \multirow{2}{*}{$\operatorname{AOR}(95 \% C I)$} \\
\hline & No $(\%)$ & Yes $(\%)$ & & \\
\hline \multicolumn{5}{|l|}{ Mode of delivery } \\
\hline Spontaneous Vaginal Delivery & $269(60.2)$ & $178(39.8)$ & $1: 00$ & $1: 00$ \\
\hline Instrumental Delivery & $5(41.7)$ & $7(58.3)$ & $2.12(0.66,6.77)$ & $1.95(0.52,7.25)$ \\
\hline Cesarean section & $21(20.2)$ & $83(79.8)$ & $5.97(3.61,10.11)^{*}$ & $4.87(2.77,8.57)^{* * *}$ \\
\hline \multicolumn{5}{|l|}{ Delivery Place } \\
\hline Institution & $285(51.6)$ & $267(48.4)$ & $4.22(1.02,21.56)^{*}$ & $2.59(0.53,12.81)$ \\
\hline \multicolumn{5}{|c|}{ Appointment forPNC service Utilization } \\
\hline No & $221(60.9)$ & $142(39.1)$ & $1: 00$ & 1:00 \\
\hline Yes & $73(36.5)$ & $127(63.5)$ & $2.71(1.90,3.89)^{*}$ & $2.55(1.71,3.82)^{* * *}$ \\
\hline \multicolumn{5}{|l|}{ PNC Complication } \\
\hline No & $243(82.7)$ & $51(17.3)$ & $1: 00$ & $1: 00$ \\
\hline Yes & $203(75.5)$ & $66(24.5)$ & $1.55(1.03,2.34)^{*}$ & $1.22(0.75,1.96)$ \\
\hline Low Knowledge & $149(57.3)$ & $111(42.7)$ & 1:00 & $1: 00$ \\
\hline Moderate Knowledge & $122(61.3)$ & $77(38.7)$ & $0.1(0.59,1.24)$ & $0.78(0.51,1.18)$ \\
\hline High Knowledge & $23(22.1)$ & $81(77.9)$ & $4.73(2.82,8.04)^{*}$ & $4.07(2.30,7.22)^{* * *}$ \\
\hline
\end{tabular}

NB-Significant association with $p$ value $<0.25^{*}, \mathrm{P}<0.05^{* *}, \mathrm{P}<0.001 * * *, 1: 00-$ Reference.

\section{Discussion}

The result of this study shows that prevalence of PNC is $47.6 \%$ and factors like Maternal Education, Mode of delivery, PNC appointment and Mothers Knowledge showed significant association with PNC utilization.

The results of the current Study were relatively higher than the finding from study in Kenya $(9.3 \%)$, and in Ethiopia (Somalia region (8.4\%), Abi Adi (11.9\%), Jabitena district (20.2\%), Debre Markos Town, (33.5\%) and in Denbecha $(34.8 \%)$ ) But lower than the finding from studies conducted in Tanzania (70.8\%), and in Ethiopia (Lemo wereda (51.4\%), Entoto fana Health center, Gulele sub city (76.2\%), and Gondar Zuria district (66.8\%) [4, 5, 7, 11-14]. This discrepancy may be due to educational status of the mothers, access to information/awareness of respondents to the use of postnatal care service. Maternal knowledge, counsel/advise and mothers who delivered in health institution to come back for postnatal care, maternal attitude have a positive effect on the importance of PNC service.

Maternal education has a strong positive association with PNC utilization. Mothers who attended secondary and above education were 2 times more likely to utilize PNC service as compared to those mothers who had no formal education. This finding was similar with study conducted in Tanzania and in Ethiopia; Gulele sub city, Addis Ababa, and Abi-Adi which shows that non educated mothers were (86\%) and (95\%) less likely to utilize PNC service respectively compared to educated women $[4,18]$. The result of current study was supported by the National survey and other studies report that, postnatal service utilization increases with women educational level [2, 4-6, 14, 18, 21]. This could be due to the fact that education has a valuable input in enhancing female autonomy and help develop greater concern about their health.

Utilization of postnatal care was significantly influenced by mode of delivery. Mothers who gave birth by cesarean section were 5 times more likely to get postnatal care service than mothers who delivered by spontaneous vaginal delivery. This is in line with study conducted in Debre Markos Town, Amhara Regional State, Ethiopia, in which mothers who delivered by cesarean section were 4.8 times more likely to get postnatal care service than who delivered by spontaneous vaginal delivery [24]. This might be due to fear of occurrence of complication and to prevent further complication which may result in increased care seeking behavior of the mothers.

The other factor associated with PNC utilization was appointment date given to mothers after delivery by health professionals. Mothers who appointed for PNC service were 2 times more likely to use the PNC service than counterparts. The result of this study is similar with the study conducted in selected Health centers in Addis Ababa town which showed that, women who were appointed after institutional delivery were more than 3 times more likely to utilize PNC service than their counterparts [9]. This may be due to that health care professionals might have informed the mothers about the benefits of PNC.

In the current study, mothers who have high Knowledge about postnatal care service and its importance were 4 times more likely to utilize the service. This result is in line with the study conducted in Debre Markos Town, Amhara, Abi Adi Town, Tigray and Wolayita Zone, Southern Ethiopian $[11,18,24]$. This can be explained by the fact that women having information, knowledge about the importance of PNC service, the service provided and the recommended time for PNC follow up may has high PNC services utilization seeking behavior.

\section{Strength and Limitation}

\subsection{Strength}

Training was given for data collectors and supervisors. 
Primary data were collected by trained female data collectors.

New data collected by face to face interview.

Since the study was community based, the result of this study can be generalized to the general population.

\subsection{Limitation}

The study design was cross-sectional, hence, the cause and effect relationship of variables were difficult to ascertain and it may not able to establish a temporal relationship.

Finally, recall bias was more likely since women were asked for events which have already happened within the past one year prior to this study.

\section{Conclusion}

The finding of this study indicated that PNC service utilization is still low, because more than $50 \%$ of women are not utilizing PNC service. Factors like Maternal Education, Mode of delivery, PNC appointment, Mothers Knowledge were found independent predictors of PNC utilization. Low utilization of PNC may contribute to increased maternal morbidity and mortality which is high in our country.

\section{Recommendations}

Government and stakeholders should work hard on increasing knowledge of community on the benefits of PNC service, Strengthen the provision of information, education and communication about postnatal care service.

All health care providers should encourage and provide post-delivery appointment for PNC service for all mothers.

Health workers should give attention to women who give birth by spontaneous vaginal delivery. Because mothers who give birth by SVD may assume that all the delivery process is normal, nothing can be occurred. But this may not be true always. Post-delivery problems may occur within 42 days. Therefore, attention should be given to mothers who give birth by SVD.

\section{List of Acronym}

$\begin{array}{ll}\text { ANC } & \text { Antenatal Care } \\ \text { AOR } & \text { Adjusted Odds Ratio } \\ \text { CI } & \text { Confidence Interval } \\ \text { COR } & \text { Crude odds Ratio } \\ \text { EDHS } & \text { Ethiopian Demographic Health Survey } \\ \text { MMR } & \text { Maternal Mortality Ratio } \\ \text { MCH } & \text { Maternal and Child Health } \\ \text { PNC } & \text { Postnatal Care } \\ \text { RH } & \text { Reproductive Health } \\ \text { SBA } & \text { Skilled Birth Attendant } \\ \text { SSA } & \text { Sub Saharan Africa } \\ \text { SVD } & \text { Spontaneous Vertex Delivery } \\ \text { WHO } & \text { World Health Organization }\end{array}$

\section{Declarations}

\section{Ethical Considerations}

Ethical clearance was obtained from the Institutional Review Board of Adama Hospital Medical College. Permission and supportive letters were received from the Adama Town Health Bureau and verbal consent was obtained from each respondent before an interview after informing the purpose and importance of the study, each participant was given full right to refuse/ to reply and discontinue the interview if any inconvenience or if she or He was not comfortable about the questionnaire. Confidentiality was assured throughout the study period. Personal identifiers were not included in the questionnaires to ensure participants' confidentiality.

\section{Consent for Publication}

Not applicable.

\section{Availability of Data and Material}

All data sets used and/or analyzed during the current study are available from the corresponding authors on reasonable request.

\section{Competing Interest}

The authors declare that they have no competing interests.

\section{Authors' Contribution}

All authors contributed into concept preparation and design, acquisition of data, analysis and interpretation of data and writing the final manuscript.

\section{Acknowledgements}

The authors want to thank respondents of the study for their answer for questionnaires and participation in the study. Finally, we want to thanks to data collectors, Supervisors for their contribution of real data collected from respondents.

\section{References}

[1] World Health Organization, Department of Maternal N Child and Adolescent Health. WHO recommendations on postnatal care of the mother and newborn [Internet]. 2013 [cited 2017 Nov 5]. Available from: http://www.ncbi.nlm.nih.gov/books/NBK190086/

[2] Reena Pal, Anita Mehndiratta. Assessment of Utilization of Postnatal Care Services in Tertiary Care Center of Delhi. June 2016. 2011 Apr; 15 (06): 04.

[3] WHO USAIDCHIPMaternal and child survival program. Postnatal Care for Mothers and Newborns Highlights from the World Health Organization 2013 Guidelines. WHO Department of Maternal, Newborn, Child and Adolescent Health http://www.who.int/maternal_child_adolescent WHO Department of Reproductive $\overline{\text { Health }}{ }^{-}$and Research http://www.who.int/reproductivehealth; 2015 Apr p. 8. (Postnatal Care Guidelines, March 2015). 
[4] Eyob Ayenew Admassu. FACTORS ASSOCIATED WITH POSTNATAL CARE UTILIZATION AT ENTOTO FANA HEALTH CENTER, GULLELE SUB-CITY, ADDIS ABABA. Int J Med Sci Public Health. 2016 Jan 20; 13.

[5] Belachew T, Taye A. Postnatal Care Service Utilization and Associated Factors among Mothers in Lemo Woreda, Ethiopia. J Womens Health Care [Internet]. 2016 [cited 2017 $\begin{array}{llll}\text { Nov } & 4] & 5 & \text { (3). Available from: }\end{array}$ http://www.omicsgroup.org/journals/postnatal-care-serviceutilization-and-associated-factors-among-mothersin-lemoworeda-ethiopia-2167-0420-1000318.php?aid=74603.

[6] Based on the 2007 Census. Centeral Statistic AgencyReport Adama, 2017. Adama: Central Statistical Agency of Ethiopia (CSA).

[7] Tesfahun F, Worku W, Mazengiya F, Kifle M. Knowledge, Perception and Utilization of Postnatal Care of Mothers in Gondar Zuria District, Ethiopia: A Cross-Sectional Study. Matern Child Health J. 2014 Dec; 18 (10): 2341-51.

[8] Lwelamira J, Safari J, Stephen A. Research Article Utilization of Maternal Postnatal Care Services Among Women in Selected Villages of Bahi District, Tanzania. 2015.

[9] Senait Berhanu Sr. Yeshi Asefa (RN, BSc, MSc), Berhanu Wordofa Giru (BSc, MSc). Prevalence of Postnatal Care Utilization and Associated Factors among Women Who Gave Birth and Attending Immunization Clinic in Selected Government Health Centers in Addis Ababa, Ethiopia, 2016. J Health Med Nurs [Internet]. 26. Available from: www.iiste.org

[10] Central Statistical Agency. Demographic and Health Survey Key Indicators [Internet]. Ethiopia; 2016 Oct p. 59. Available from: Internet: www.DHSprogram.com.

[11] Wolde Facha,, Mihretu Alemayehu, Mengistu Meskele, Teshale Fikadu. Couples' Opinion and Women's Utilization of Postnatal Care Service in Wolaita Zone, Southern : A Community Based Mixed Study. May 20 2017. 2017 Apr 6; 05, (2328-7942, 2328-7950): 288-93.

[12] Wubareg Seifu, and Beyene Meressa. Maternal Health Care Service Utilization and Associated Factors among Pastoral and Agro Pastoral Reproductive Age Women Residing in Jigjiga Town, Somali Regional State, Eastern Ethiopia. Public Health Dep Epidemiol Biostat. 2017 Mar 10; 06 (02): 7.

[13] Tsegay Y, Gebrehiwot T, Goicolea I, Edin K, Lemma H, Sebastian M. Determinants of antenatal and delivery care utilization in Tigray region, Ethiopia: a cross-sectional study. Int J Equity Health. 2013; 12 (1): 30.

[14] Ayana Hordofa M. Postnatal Care Service Utilization and Associated Factors Among Women in Dembecha District, Northwest Ethiopia. Sci J Public Health. 2015; 3 (5): 686.

[15] Gedefaw M, Muche B, Aychiluhem M. Current Status of Antenatal Care Utilization in the Context of Data Conflict: The Case of Dembecha District, Northwest Ethiopia. Open J Epidemiol. 2014; 04 (04): 208-16.
[16] Dulla D, Daka D, Wakgari N. Antenatal Care Utilization and Its Associated Factors among Pregnant Women in Boricha District, Southern Ethiopia. Divers Equal Health Care. 2017.

[17] Factors associated with postnatal care utilisation in Rwanda: A secondary analysis of 2010 Demographic and Health Survey data. Online 2016 May 31 [Internet]. 2016; 16. Available from: (http://dhsprogram.com/data/availabledatasets.cfm).

[18] Alemayeh H, Assefa H, Adama Y. Prevalence and Factors Associated with Post Natal Care Utilization in Abi-Adi Town, Tigray, Ethiopia: A Cross Sectional Study. 2014 Nov; 08 (01).

[19] Daniel Akunga, a, Diana Menya, b, and Mark Kabue. Determinants of Postnatal Care Use in Kenya. Afr Popul Stud. 2014; 28 (03): 13.

[20] Bhaisare K, a, Diana Menya, b, and Mark Kabue. Study of utilization of postnatal care services in tribal area, Maharashtra. Int J Med Sci Public Health. 2014; 3 (12): 1487.

[21] Gebeyehu Workineh Y. Factors Affecting Utilization of Postnatal Care Service in Amhara Region, Jabitena District, Ethiopia. Sci J Public Health. 2014; 2 (3): 169.

[22] Muluw, as Amentie, Muluemebetabera \& Misra abdulahi. Util ization of Institutional Delivery Care Services and Influencing Factors among Women of Child Bearing Age in Assosa District, Benishangul Gumuz Regional State, West Ethiopia. Glob J Inc USA. 2016 Year; 16 (3): 11.

[23] Mrisho M, Obrist B, Schellenberg JA, Haws RA, Mushi AK, Mshinda $\mathrm{H}$, et al. The use of antenatal and postnatal care: perspectives and experiences of women and health care providers in rural southern Tanzania. BMC Pregnancy Childbirth [Internet]. 2009 Dec [cited 2017 Nov 5]; 9 (1). Available from: http://bmcpregnancychildbirth.biomedcentral.com/articles/10. 1186/1471-2393-9-10

[24] Limenih MA, Endale ZM, Dachew BA. Postnatal Care Service Utilization and Associated Factors among Women Who Gave Birth in the Last 12 Months prior to the Study in Debre Markos Town, Northwestern Ethiopia: A CommunityBased Cross-Sectional Study. Int J Reprod Med. 2016; 2016: $1-7$.

[25] Central Statistical Agency, Addis Ababa, Ethiopia, MOH. Ethiopia Mini Demographic and Health Survey [Internet]. Addis Ababa, Ethiopia: Statistical Agency; 2014 Aug p. 112. Available from: Avilable from Fax: (251) 111550334.

[26] USAID C. Cultural Barriers to Seeking Maternal Health Care in Ethiopia: A Review of the Literature. 2012 Dec; 29.

[27] Woldegiorgis MA, Bhowmik JL, Hiller JE, Mekonnen W. Trends in Reproductive Health indicators in Ethiopia: 20002014. Int J Healthc [Internet]. 2016 Dec 12 [cited 2017 Nov 5]; 3 (1). Available from: http://www.sciedupress.com/journal/index.php/ijh/article/view $/ 10238$ 